\title{
Exploring Negative Beliefs About Power
}

\author{
The Role of Autonomy and Influence
}

\author{
Tobias Wingene and Simone Dohle(0) \\ Social Cognition Center Cologne, University of Cologne, Germany
}

\begin{abstract}
The powerful are immoral"! Across four preregistered studies (total $N=2,744$ ), we explored the role of perceived autonomy (control over own resources) and perceived influence (control over others' resources) for this belief. In Study 1, perceived autonomy and influence mediated the effect of power on expected immorality. Likewise, directly manipulating perceived autonomy and influence led to increased expected immorality, increased perceived intentionality of a transgression, and consequently to harsher punishment recommendations (Studies 3 and 4). Interestingly, Study 2 revealed an interaction between autonomy and influence, which we however could not replicate in Study 4. Overall, our findings suggest that both autonomy and influence are associated with immorality and thus likely drive the belief that the powerful are immoral.
\end{abstract}

Keywords: power, influence, autonomy, immorality, intentionality

The belief that powerful people are immoral is deeply ingrained in Western culture. Powerful people are generally perceived as dominant and cold (Fragale et al., 2011). Likewise, people believe that different immoral behaviors, such as cheating and lying, are much more typical for the powerful than for the powerless (Hu et al., 2016). Furthermore, the powerful play a central role in almost all conspiracy beliefs (Imhoff \& Bruder, 2014), and powerful individuals are perceived as more intentional wrongdoers than less powerful individuals (Fragale et al., 2009). On a group level, groups high on agency (i.e., power and status) are perceived as less warm and trustworthy than groups with an average agency (Imhoff \& Koch, 2017). Some negative beliefs about power seem to be learned early in life: Even preschoolers believe that powerful leaders are less likely to behave prosocially (e.g., sharing a cookie) than their subordinates (Thomas et al., 2020).

These negative beliefs about the powerful can have negative consequences for the powerful and the powerless. Facing (global) calamities, such as climate change or pandemics, modern societies heavily rely on cooperation (e.g., Tavoni et al., 2011). Yet, negative beliefs about power might hinder cooperation and foster conflicts between the powerful and the powerless. For example, people might avoid cooperating with the powerful, as they expect interactions to be negative (Fragale et al., 2011). Cooperation might be especially reduced when cooperation relies on trust because negative expectations toward the powerful can lead them to be perceived as untrustworthy (Soderberg, 2017). Negative beliefs about the powerful can also lead people to recommend harsher punishments for powerful transgressors, even if the intentionality of the transgression is unclear (Fragale et al., 2009). Such negative beliefs might also explain why people sometimes show a preference against powerful roles (Hays, 2013; Schmid Mast \& Hall, 2003). Indeed, lower-class individuals are less likely to seek power since they believe that doing so would require engaging in immoral behaviors (Belmi \& Laurin, 2016), which could contribute to class-based inequality.

\section{Understanding Beliefs About Power Through Autonomy and Influence}

Given these important consequences of negative beliefs about power, we here seek to better understand their psychological antecedents and ask the question of why people believe that the powerful are immoral. We here define power as "the ability to control resources, own and others" (Galinsky et al., 2003, p. 454). This definition contains two elements: Control over others' resources and outcomes, which has been conceptualized as influence, and control 
over own resources and outcomes, which has been conceptualized as autonomy ${ }^{1}$ (Lammers et al., 2016). According to this definition of power, both autonomy and influence are integral elements of power, and we here thus conceptualize them as different aspects of power.

A recent literature review suggests that the autonomy/influence distinction is also part of other common definitions of power, albeit less visibly (Lammers et al., 2016). Specifically, Fiske and Berdahl (2007, p. 679) defined power as "relative control over another's valued outcomes." The word relative is crucial and implies that power is not only characterized by the capacity to control others' resources (influence) but also by whether others have control over their own resources (autonomy). Likewise, Keltner and colleagues (2003, p. 265) highlighted this relative nature of power by defining power as "relative capacity to modify others' states." Thus, also other common definitions hint toward the autonomy/influence distinction (for a detailed discussion on this distinction see Lammers et al., 2016).

Often, powerful individuals equally enjoy both aspects of power: They hold influence over others, but at the same time, they enjoy high autonomy for themselves. Nevertheless, a variety of scholars recently tested whether holding autonomy and influence has different psychological consequences (Cislak et al., 2018; Lammers et al., 2009, 2016; Leach et al., 2017; Van Dijke \& Poppe, 2006). This work demonstrated that this distinction is also empirically relevant. They found that autonomy and influence can have distinct psychological effects, for example, on stereotyping (Lammers et al., 2009), aggressiveness and exploitative behavior (Cislak et al., 2018), and on the desire for power (Lammers et al., 2016; Van Dijke \& Poppe, 2006).

Importantly, autonomy and influence, as defined by Lammers and colleagues (2016), can in principle be used to reach moral and immoral goals. For instance, people can use their influence to help or to harm others by providing or withholding resources. Likewise, people with high autonomy can use their freedom for the good or abuse it for the bad. This points to a key difference between the autonomy/influence distinction used in this paper (following Lammers et al., 2016) and other distinctions in the power literature. For example, building on classic work (McClelland, 1970; Winter, 1973), Torelli and Shavitt (2010) differentiated between power in personalized terms (i.e., power for advancing one's personal status and prestige) and power in socialized terms (i.e., power for benefiting and helping others). Likewise, Sassenberg and colleagues (2012) distinguished between power as an opportunity for one's own goal achievement versus power as responsibility (i.e., focusing on the implications of one's actions for others). Finally, various approaches suggest a moral or immoral nature of power depending on motives and values of the powerful, such as their relationship orientation (Chen et al., 2001), or social-value orientation (Guinote et al., 2012). Overall, all these approaches thus differ from our autonomy/influence distinction by pointing to moral versus immoral aspects of power, whereas the autonomy/influence distinction does not inherently require such a distinction (for a related argumentation see Lammers et al., 2016).

As autonomy and influence are by our definition (following Lammers et al., 2016) not necessarily moral or immoral, it seems particularly interesting to investigate how non-scientists perceive these aspects of power. First, it has not yet been tested whether non-scientists, in line with our theoretical reasoning, also see autonomy and influence as central aspects of holding power. Second, it has not yet been investigated whether autonomy and influence drive beliefs about power, especially the belief that the powerful are immoral. Do people believe that autonomous individuals are immoral, or that influential individuals are immoral, or both?

While work in this area is still in its early stages, it provides arguments for different perspectives. On the one hand, autonomy might drive the belief that the powerful are immoral. Autonomy allows the powerful to follow their own needs and goals without external control, which is central to the experience of power (Guinote, 2007). This freedom from others that the powerful experience has effects similar to anonymity (Hirsh et al., 2011). It leads the uncontrolled powerful to behave disinhibited (Keltner et al., 2003) and to ignore social norms (Lammers \& Imhoff, 2016). It seems likely that the image of autonomous individuals, who can fulfill their own needs and desires without any external control, evokes expectations of immorality. It thus seems possible that people expect individuals who have uncontrolled power (i.e., autonomy) to behave rather immorally.

On the other hand, influence might drive the belief that the powerful are immoral. Already classic definitions of power, such as the definition by sociologist Max Weber "power means every chance (no matter where on this chance is based) to carry through the own will (even against resistance)." (Wallimann et al., 1977, p. 234) included that the powerful impose their will on others. Indeed, by exerting influence the powerful simultaneously limit other people's autonomy. Autonomy is often considered a central

\footnotetext{
1 Past work also used the terms personal and social power (Lammers et al., 2009) to describe autonomy and influence, but this terminology was dropped (Lammers et al., 2016) to avoid confusion with other usages of the term social power (such as Fiske \& Berdahl, 2007). However, it should be noted that also the usage of the term influence can be ambiguous, as influence has also been conceptualized differently, for example, as downstream consequence of power (Fiske, 2010; French \& Raven, 1959).
} 
human need (Deci \& Ryan, 2000), and being deprived of autonomy leads people to experience reactance and negative emotions (Brehm, 1966; Steindl et al., 2015). It seems likely that preventing people from fulfilling their central needs is per se perceived as immoral. Indeed, unlawful deprivation of liberty is even considered to be a crime in modern societies. Likewise, Fragale and colleagues (2011) hypothesized that the powerful are perceived as cold because their power constrains the freedom of others. To sum up, it seems possible that influential individuals are generally perceived as immoral, as influence implies imposing one's own will on others.

\section{The Present Research}

The present research tested these contradicting predictions and explored the role of autonomy and influence for people's beliefs about power. We expected people to believe that the powerful are immoral, and to perceive autonomy and influence as central aspects of power. As discussed above, both autonomy and influence might drive the negative perception of power, and we were initially agnostic about which aspect plays a more dominant role. This was thus an exploratory research question. We describe central hypotheses and exploratory research questions in more detail when introducing each study.

Study 1 examined whether people indeed see autonomy and influence as central aspects of power and tested whether these variables mediate the effect of perceived power on expected immorality. Studies $2-4$ directly tested expectations toward people who hold autonomy and/or influence. We tested effects on expected immorality (Study 2), attributed intentionality in case of a transgression, namely tax evasion (Study 3), and both (Study 4). We consider tax evasion to be a form of immoral behavior, as tax evasion is selfish behavior that is judged as unacceptable by the larger community, thereby meeting various definitions of immorality (Dubois et al., 2015).

We include all studies we conducted, and report all collected variables and conditions included in the study designs across all studies. We report all preregistered analyses in the manuscript or Electronic Supplementary Material, ESM 1, and highlight non-preregistered analyses. We exploratory tested whether our central findings depend on participants' age, gender, or social class and present these analyses in full detail in ESM 1. All participants who completed our studies were included in the analyses unless they met preregistered exclusion criteria. Participants who took part in one of our studies were not allowed to participate in subsequent studies. This research project was reviewed and approved by the local institutional review board. Materials, data, analyses syntaxes, and preregistrations are shared on https://osf.io/qfjtv/.

\section{Study 1}

Study 1 tested the central assumptions of this research project. First, Study 1 tested whether people indeed expect the powerful to be more immoral than the powerless. Moreover, Study 1 tested whether people perceive the powerful to be more autonomous and influential than the powerless. Even though autonomy and influence are in our theorizing both central aspects of power, it remains possible that this is not reflected in lay beliefs about power. For example, manipulating power might only affect perceived influence, but not autonomy, or vice versa. We, however, expected significant effects of described power on both perceived autonomy and influence, and on excepted immorality.

Study 1 further exploratory tested whether perceived autonomy and/or influence mediate the effect of power on expected immorality. Even if non-scientists perceive the powerful to be autonomous and influential (as predicted), it is unknown whether perceived autonomy or influence then in turn both correlate with expected immorality. Such correlations would indicate that perceptions of the described group's autonomy/influence are associated with beliefs about their expected immorality. Going beyond zero-order correlations, a parallel mediation model could then provide initial evidence regarding which aspects of power drives non-scientists negative perceptions. Crucially, such a model allows disentangling the effects of autonomy and influence by simultaneously including both aspects into one mediation model. Further, such a model allows testing whether perceived autonomy and influence fully mediate the effect of power on expected immorality. If this model instead only reveals a partial mediation, this could suggest that additional aspects are relevant for negative beliefs about power.

\section{Method}

\section{Participants and Design}

We recruited 428 Amazon MTurk users for US \$0.75, and randomly assigned them to either a high-power or lowpower condition. We used a hidden attention check ("If you read this, choose strongly disagree") to avoid inattentive responses and to increase the quality of our data (Hauser \& Schwarz, 2016). Thirty-one participants provided no correct response to this hidden attention check and were thus excluded from data analyses following our preregistration, leaving 397 individuals (224 male, 167 female, 2 diverse, 4 missing; $M_{\text {age }}=35.61, S D=9.90$ ).

Our sample size was not based on formal power analyses, which is not available for parallel mediation models in commonly used software, but instead relied on prior research utilizing similar sample sizes for parallel mediation models (Cislak et al., 2018; Wingen et al., 2020). However, a 
sensitivity analysis using the $\mathrm{R}$ package pwr (Champely et al., 2018) revealed that we had an $80 \%$ power to detect a total effect of $d=0.25$ of perceived power on any of the dependent variables and a $95 \%$ power to detect $d=0.33$.

\section{Imagined Power}

Participants reported the expectations they held for people with high or low power (following $\mathrm{Hu}$ et al., 2016). Participants were provided with a brief definition of what was meant by power and were assigned to indicate the expectations toward either powerful or powerless individuals. Specifically, participants read a paragraph that stated, "Power is defined as having control over valued resources. In real life, some people possess power while some people lack power. In the current task, we are curious about your expectations for those who possess (lack) power" (Hu et al., 2016, p. 829). Participants were then asked to take a moment to imagine how those who possess (lack) power usually behave.

\section{Manipulation Check}

Participants indicated the level of power of the people they just imagined on a 7 -point item $(1=$ lack power, $7=$ have power).

\section{Perceived Autonomy and Perceived Influence}

Participants indicated whether they believed that the people they just imagined have influence ("lead other people," "influence other people," "are in control of other people," and "are responsible for other people"; $\alpha=.96$ ) and autonomy ("are able to do whatever they want to do," "can follow their own wishes or desires," "can freely choose to do whatever they want," "are independent from other people"; $\alpha=.96)$. Perceived influence and autonomy were measured with four items for each construct on 7-point Likert-scales ranging from 1 (= strongly disagree) to 7 (= strongly agree). These scales were adapted from prior research, in which they were used to measure individuals' own (instead of others' perceived) autonomy and influence (Lammers et al., 2016). A non-preregistered factor analysis confirmed the distinctiveness of the measures, as a two-factor model differentiating autonomy and influence performed significantly better than a one-factor model, $\Delta \chi^{2}=343.45, p<$ .001 (see ESM 1 for details).

\section{Hidden Attention Check}

As seemingly the last item of the influence scale, the hidden attention check ("If you read this, choose strongly disagree") was administered.

\section{Expected Immorality}

Next, participants completed a measure of expected immorality, taken from prior research (Hu et al., 2016, p. 829). In this measure, participants received four immoral behaviors ("cheat," "behave immorally," "tell a lie," and "perform actions that serve their self interests"; $\alpha=.93$ ) and indicated whether each behavior is typical for the people they just imagined. Answers were given on a 7-point rating scale, ranging from 1 (= definitely not consistent) to 7 (= definitely consistent).

\section{Demographics}

Finally, participants reported their age, gender, and subjective social class (Adler et al., 2000), were provided with contact details for further questions and were rewarded through the MTurk online system.

\section{Results}

Power Increases Autonomy, Influence, and Immorality The manipulation check was successful $(p<.001, d=2.59$, see ESM 1). In addition and as predicted, participants in the high-power-condition reported a higher perceived autonomy $(M=5.77, S D=1.02)$ than participants in the low power-condition $(M=2.76, S D=1.55), t(395)=22.78, p<$ $.001, d=2.29,95 \%$ CI $[2.03,2.54]$. Moreover, participants in the high-power-condition reported a higher perceived influence $(M=5.88, S D=0.92)$ than participants in the low power-condition $(M=2.22, S D=2.22), t(395)=29.71, p<$ $.001, d=2.98,95 \%$ CI [2.70, 3.27]. Finally, we found that participants indeed expected the powerful to be immoral. Participants in the high-power-condition reported a higher expected immorality $(M=4.74, S D=1.49)$ than participants in the low power-condition $(M=3.61, S D=1.57), t(394)=$ $7.35, p<.001, d=0.74,95 \%$ CI $[0.53,0.94]$.

An exploratory analysis suggested that this effect of imagined power was reduced for people with a higher subjective social class $(B=0.36, p<.001$, see ESM 1$)$.

Within both conditions, imagined power (i.e., the manipulation check), perceived autonomy, perceived influence, and expected immorality all correlated positively and significantly with each other. These correlations are displayed in Figures 1 and 2.

\section{Mediation Analysis}

We then investigated whether autonomy and/or influence mediated the effect of power on expected immorality. To test this, we ran a parallel mediation model (see Figure 3) with 10,000 bootstrap resamples, using the $\mathrm{R}$ package lavaan. This model revealed that autonomy and influence fully mediated the effect of power on expected immorality since the direct path was not significant after including the mediators in the model. Regarding the indirect effects, only influence $(b=0.70,95 \%$ CI $[0.12,1.29])$, but not autonomy $(b=0.47,95 \%$ CI $[-0.06,0.97])$, was significant, indicated by the confidence interval (CI) not including zero. 

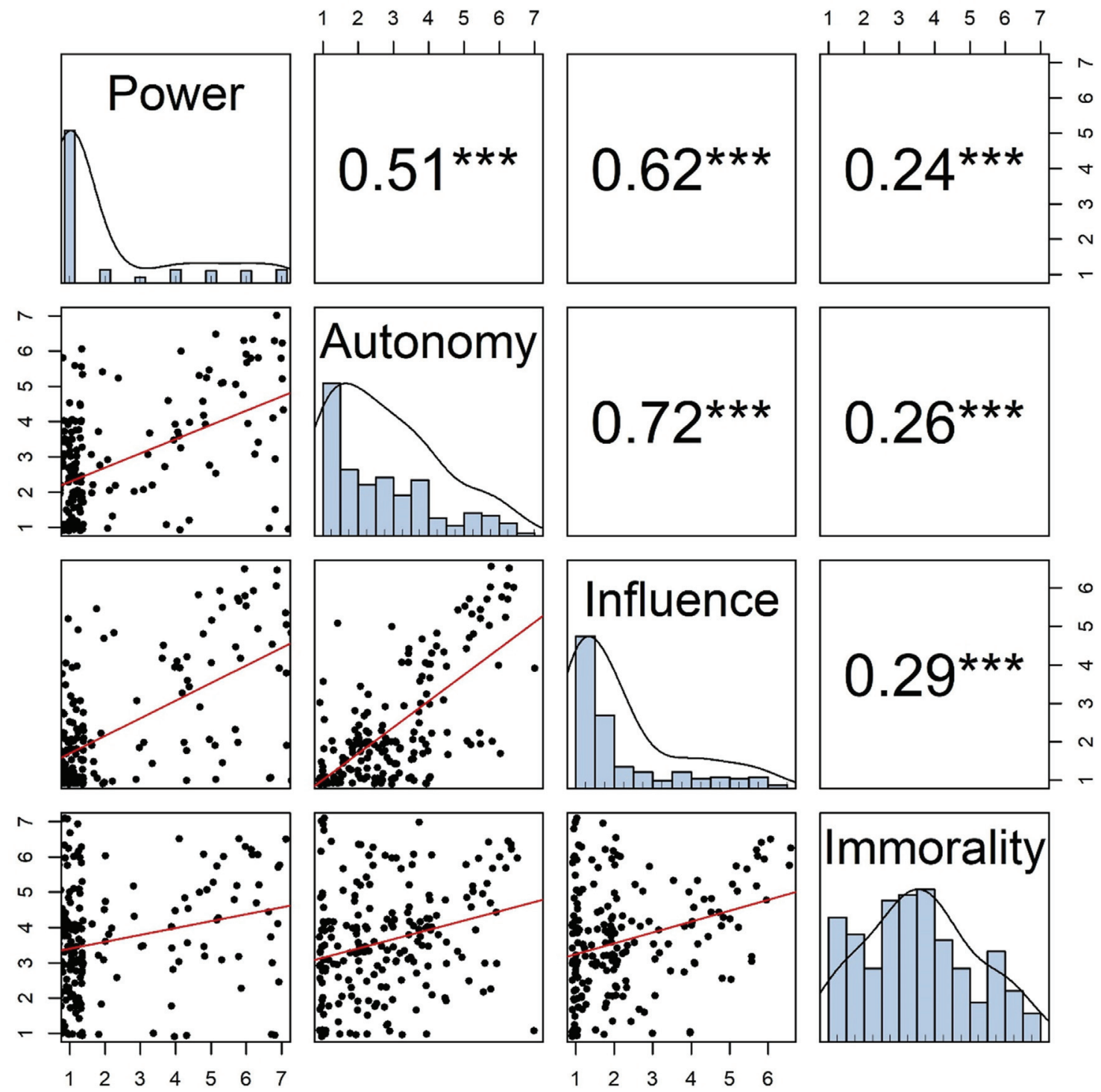

Figure 1. Scatter plot matrix displaying relationships between imagined power (manipulation check), perceived autonomy, perceived influence, and expected immorality in the low power-condition. The figure includes bivariate scatter plots with regression line (red) below the diagonal, histograms on the diagonal, and correlations above the diagonal. ${ }^{* \star} p<.001$. Correlations were not preregistered.

However, the difference between the two indirect effects was not by itself significant $(b=0.23,95 \%$ CI $[-0.77$, 1.27]). We assessed exploratory whether autonomy and influence interacted with each other, but this was not the case, $p=.233$ (see ESM 1).

\section{Discussion}

Study 1 confirmed our central hypotheses. First, powerful people were indeed expected to behave more immorally than powerless people. Second, imagined power had large effects on perceived autonomy and influence, indicating that autonomy and influence are central to beliefs about power. Finally, our findings suggest that the effect of power on expected immorality is fully mediated by perceived autonomy and influence. However, their indirect effects were not significantly different, and perceived autonomy and influence both correlated with expected immorality. Thus, the results did not allow to conclusively disentangle their effects on expected immorality. Moreover, Study 1 employed a measurement-of-mediation design (Spencer et al., 2005), which does not allow for definite causal claims. This is because the mediating variables were not experimentally manipulated (Bullock et al., 2010) and many different explanations, beyond genuine mediation, can thus explain an observed significant mediation (Fiedler et al., 2011). 

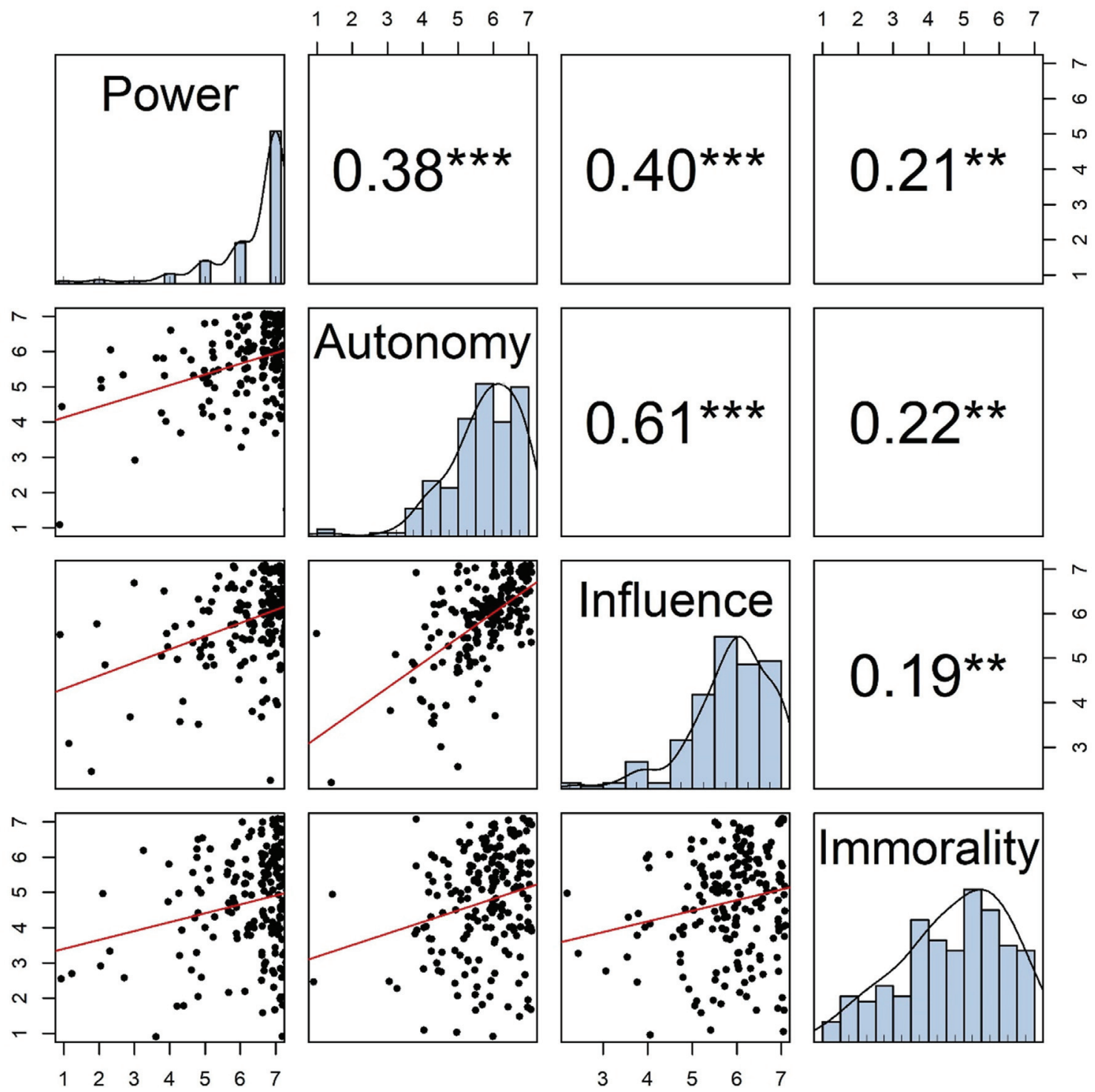

Figure 2. Relationships between imagined power (manipulation check), perceived autonomy, perceived influence, and expected immorality in the high power-condition. ${ }^{*} p<.01 ; * \star * p<.001$.

\section{Study 2}

If mediating variables can be manipulated, experimentalcausal-chain designs (Spencer et al., 2005) are superior in testing psychological processes. Study 1 demonstrated causal effects of power on perceived autonomy, influence, and expected immorality. Study 2 followed the causal chain from power to expected immorality by directly manipulating the two (potentially mediating) aspects of power: perceived autonomy and influence. In Study 2, we thus tested the causal effects of autonomy and influence on expected immorality. Study 2 further moved from describing a whole group to describing an individual, as we believed that it would be easier for participants to imagine a specific person having, for example, low autonomy and high power, compared to a whole group. Study 2 was exploratory and had no hypothesis on whether autonomy or influence would cause increased expected immorality.

\section{Method}

\section{Participants and Design}

We recruited 419 MTurk users for US\$ 0.75, and randomly assigned them to one of four conditions, resulting from a 2 (described autonomy: low vs. high) $\times 2$ (described influence: low vs. high) between-participants design. Nineteen participants failed our attention check (identical to Study 1), leaving 400 participants ( 239 male, 157 female, 3 diverse, 1 missing; $M_{\text {age }}=36.09, S D=10.89$ ). 


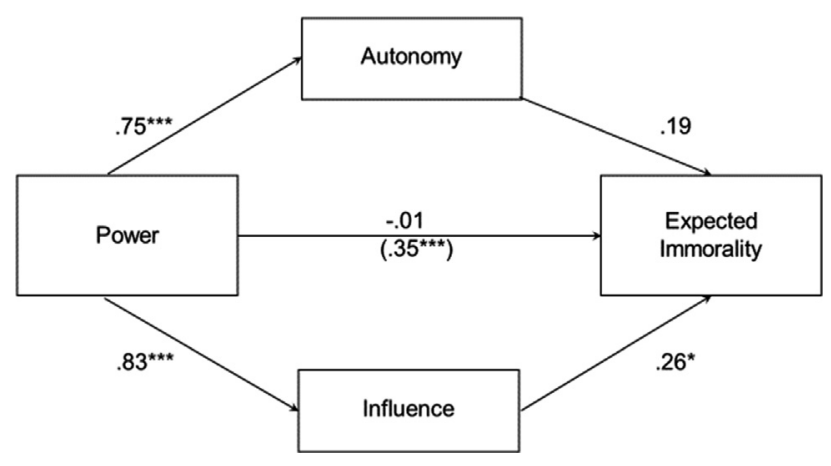

Figure 3. Parallel mediation analyses involving perceived autonomy and influence as dual, simultaneous mediators for the link between imagined power and expected immorality. Values represent standardized path coefficients. The total effect is presented in parentheses. ${ }^{*} p<.05 ;{ }^{* *} p<.001$.

Our sample size was again not based on formal power analysis since the effects of perceived autonomy and influence on expected immorality were unknown. Instead, we aimed to recruit a relatively large number of 100 participants per cell. A sensitivity analysis using $\mathrm{G}^{*}$ Power 3.1.9.2 (Faul et al., 2017) revealed that we had a $80 \%$ power to detect an effect of $f=.14\left(\eta^{2}=.02\right)$, and a 95\% power to detect $f=.18\left(\eta^{2}=.03\right)$.

\section{Autonomy and Influence Manipulation}

Participants read a brief description of a person (John). Depending on the condition, John was described as having high or low autonomy and high or low influence. The attributes to manipulate autonomy and influence were directly taken from prior work (Lammers et al., 2016). Importantly, we gave no further indication of John's total power, as we aimed to manipulate the different aspects of power (autonomy and influence) and not overall power. Participants were asked to read the description and to imagine John's typical behavior. For example, in the high autonomy and high influence-conditions participants read (texts for the low autonomy and low influence-conditions are presented in parentheses):

John is pretty (not very) autonomous in his everyday life. Usually, he can (cannot) do whatever he wants and (he cannot) make free decisions. Other people normally do not (often) get in his way.

He is not only (In addition to being not) very autonomous, but he is also (not) a leader for others. He has (does not have) employees and (or) other people that he is in charge of and he is typically (not) influencing and controlling others.

\section{Manipulation Check}

Participants indicated whether the person they just imagined "is autonomous" and "has influence over other people" on 7-point Likert-items ranging from 1 (= disagree) to 7 (= agree).

\section{Expected Immorality}

Next, participants again completed the measure of expected immorality (Hu et al., 2016), utilized in Study 1 $(\alpha=.86)$. They indicated for each immoral behavior whether it would be typical for the person they just imagined.

\section{Demographics}

Like in Study 1, participants finally reported their age, gender, and subjective social class, were provided with contact details for further questions and were rewarded through the MTurk online system.

\section{Results}

\section{Manipulation Checks}

The manipulation checks indicated that our manipulation was successful (both $p s<.001$, both $d s>2.29$, see ESM 1). Importantly, we observed no significant effect of our autonomy manipulation on the influence manipulation check and vice versa (both $p$ s $>.468$, both $d$ s $<0.08$, see ESM 1).

\section{Main Analysis}

We then submitted ratings of expected immorality to a 2 (described autonomy: low vs. high) $\times 2$ (described influence: low vs. high) between-participants analysis of variance (ANOVA). This ANOVA revealed a main effect of autonomy, $F(1,396)=4.23, p=.040, \eta_{\mathrm{p}}^{2}=.011,90 \% \mathrm{CI}$ [.0002, .033], ${ }^{2}$ but no significant main effect of influence, $F(1,396)=2.77, p=.097, \eta_{\mathrm{p}}^{2}=.007,90 \%$ CI [.000, .027].

Importantly, a significant interaction emerged between perceived autonomy and influence, $F(1,396)=5.43, p=$ $.020, \eta_{p}^{2}=.014,90 \%$ CI [.001, .038]. This interaction is depicted in Figure 4. Non-preregistered $t$-tests revealed that the person described as influential but low on autonomy $(M=2.98, S D=1.43)$ was expected to be less immoral than all other conditions, that is the high autonomy high influence condition $(M=3.60, S D=1.44), t(192)=3.01, p=$ $.003, d=0.43,95 \%$ CI $[0.15,0.72]$, the high autonomy low influence condition $(M=3.51, S D=1.36), t(200)=$ $2.68, p=.008, d=0.38,95 \%$ CI $[0.10,0.66]$, and finally the low autonomy low influence condition $(M=3.55$, $S D=1.42), t(208)=2.87, p=.005, d=0.40,95 \% \mathrm{CI}$

\footnotetext{
${ }^{2} \eta^{2}$ and $\eta_{p}^{2}$ are squared, and thus always positive. Therefore, a 95\% $\mathrm{Cl}$ around Cohen's $d$ equals a $90 \% \mathrm{Cl}$ around $\eta^{2}$ for an identical test. We thus calculate $90 \% \mathrm{Cls}$ around $\eta^{2}$ p , following established statistical recommendations (Lakens, 2014).
} 
$[0.12,0.67]$. All other conditions did not significantly differ in expected immorality (all $p \mathrm{~s} \geq .64$, all $t \mathrm{~s} \leq 0.46$, all $d \mathrm{~s} \leq 0.08)$, as displayed in Figure 4 .

\section{Discussion}

Study 2 revealed an unpredicted interaction of perceived autonomy and influence. Participants reported the least expected immorality when they judged an individual low on autonomy but high on influence. Interestingly, the findings in Study 2 are rather different from Study 1. Whereas in Study 1 perceived autonomy and influence had rather parallel effects and fully mediated the effect of power on expected immorality, we found no evidence for this in Study 2. Even though the high autonomy and high influence conditions were indeed perceived as the most immoral, this condition did not significantly differ from the low autonomy and low influence conditions. This suggests that autonomy and influence might not both be tied to expected immorality. As Study 1 (correlational) and Study 2 (experimental) relied on very different designs, it is not too surprising that they led to different results. However, the experimental method utilized in Study 2 is in general considered superior in revealing causal effects (Spencer et al., 2005).

\section{Study 3}

Study 2 suggested that being low on autonomy but influential is particularly beneficial for one's moral reputation. However, given the contrasting findings of Studies 1 and 2, we aimed to conceptually replicate this pattern in Study 3. Moreover, we wanted to test the applied relevance in a tax evasion scenario in which the intentionality of the wrongdoing was unclear. We expected that perceived intentionality in case of a transgression would mirror the findings regarding expected immorality in Study 2. We thus expected people who read about a person low on autonomy but high on influence to report the lowest perceived intentionality and subsequently to recommend the most lenient punishment, compared to all other groups.

\section{Method}

\section{Participants and Design}

A power analysis using $G^{*}$ Power 3.1.9.2 (Faul et al., 2017) showed that we needed 950 participants to replicate the interaction between autonomy and influence found in Study $2\left(1-\beta=.95, \alpha=.05, \eta_{p}^{2}=.014\right)$.

To compensate for potential exclusions, we recruited 1,021 MTurk users for US\$0.75, and randomly assigned

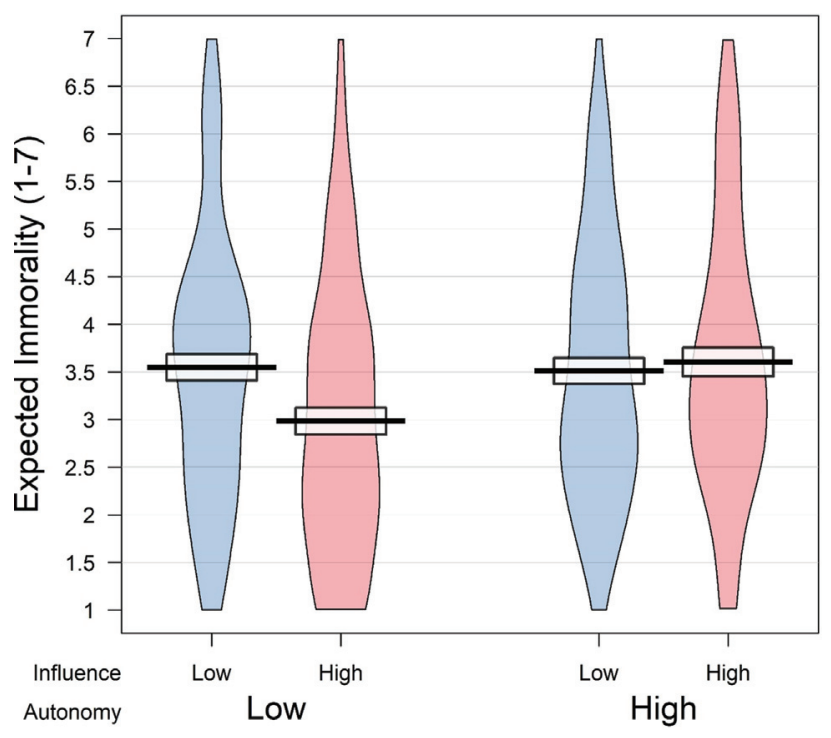

Figure 4. Pirate plot (Phillips, 2017) showing expected immorality as a function of perceived autonomy and influence in Study 2. The colored beans are smoothed densities indicating the distributions in each condition. The central tendency is the mean, and the intervals represent two standard errors around the mean.

them to one of four conditions, resulting from a 2 (described autonomy: low vs. high) $\times 2$ (described influence: low vs. high) between-participants design.

We again used a hidden attention check. Forty-one participants provided no correct response to this check and were thus excluded, leaving a final sample size of 964 individuals (510 male, 448 female, 4 diverse, 2 missing; $M_{\text {age }}=$ $37.68, S D=11.63)$.

\section{Autonomy and Influence Manipulation}

First, participants read the same description as in Study 2, describing a person (John) who either had high or low influence and high or low autonomy. Participants were again asked to read the description and to imagine the person's typical behavior.

\section{Manipulation Checks}

The manipulation checks were identical to Study 2.

\section{Tax Evasion Scenario}

Participants were then presented with a tax evasion scenario, taken from prior research (Fragale et al., 2009). This short scenario explained that the described person, John, recently was accused by the Internal Revenue Service of underpaying the federal government on his income taxes. The scenario then clarified that it is unclear whether this was a mistake, or an intentional attempt to pay fewer taxes.

\section{Attributions of Intentionality and Attention Check}

Participants indicated how likely it was that John intentionally decided to evade taxes with 3 items ("John decided to 
understate his taxes with full awareness of the tax laws," "John inadvertently understated his taxes due to ignorance of the tax laws," "John's actions were due to a lack of awareness of the tax laws; $\alpha=.79$ ) adapted from prior work (Fragale et al., 2009). Answers were given on a 7-point rating scale ranging from 1 (= very unlikely) to 7 (= very likely).

As seemingly the last item of the intentionality scale, the hidden attention check ("If you read this, choose very unlikely") was administered.

\section{Recommended Punishment}

Participants also answered four questions to assess their recommended punishment adapted from prior work (Fragale et al., 2009). Participants completed four items asking whether (1) "John should be punished by the IRS" ( 1 =definitely not; 7 = definitely), (2) "If John was punished, his punishment should be" $(1=$ not at all severe; $7=$ very severe), (3) "Paying back the money that he owed the IRS would be a sufficient punishment" ( $1=$ not at all sufficient; 7 = completely sufficient), and (4) "The IRS should impose an additional penalty above and beyond the repayment of the owed taxes" $(1=$ definitely not; $7=$ definitely $)$.

\section{Demographics}

As in the previous studies, participants finally reported their age, gender, and social class, were provided with contact details for further questions and were rewarded through the MTurk online system.

\section{Results}

\section{Manipulation Checks}

The manipulation checks indicated that our manipulation was successful (both $p s<.001$, both $d s>2.63$, see ESM 1). Moreover, we observed only comparably very small effects of our autonomy manipulation on the influence manipulation check and vice versa (both $p \mathrm{~s}<.025$, both $d$ s $<0.22$, see ESM 1).

\section{Intentionality}

We then conducted a 2 (described autonomy: low vs. high) $\times 2$ (described influence: low vs. high) between-participants ANOVA with mean intentionality ratings as the dependent variable. This ANOVA revealed main effects of autonomy $F(1,960)=86.35, p<.001, \eta_{\mathrm{p}}^{2}=.083,90 \%$ CI [.057, $.111]$, and influence, $F(1,960)=40.25, p<.001, \eta_{p}^{2}=$ $.040,90 \%$ CI [.022, .062], as well as a small orthogonal interaction, $F(1,960)=4.53, p=.034, \eta_{\mathrm{p}}^{2}=.005,90 \%$ CI [.0002, .015].

Participants in the high autonomy conditions reported a higher perceived intentionality $(M=3.53, S D=1.42)$, than participants in the low autonomy conditions $(M=2.75$, $S D=1.24)$. Moreover, participants in the high influence conditions reported more perceived intentionality ( $M=$ $3.41, S D=1.47$ ), than participants in the low influence conditions $(M=2.87, S D=1.24)$. This pattern is depicted in Figure 5 and differs from our prediction.

\section{Recommended Punishment}

Perceived autonomy $\left(p=.001, \eta_{\mathrm{p}}^{2}=.013\right)$ and influence $\left(p=.004, \eta_{p}^{2}=.009\right)$ also led to increased punishment recommendations and these effects were mediated by perceived intentionality (see ESM 1 for details).

\section{Discussion}

Being autonomous and influential was both associated with increased perceived intentionality in case of a transgression. This suggests that gaining autonomy and influence can have detrimental effects. Indeed, supplementary mediation analysis suggests that perceived intentionality subsequently increased punishment recommendations. Interestingly, the findings differ from the interaction pattern observed in Study 2. We addressed this inconsistency in Study 4.

\section{Study 4}

Study 4 had three main goals. First, in light of our mixed findings, we aimed to test whether our findings from Studies 2 and 3 were replicable. We thereby aimed to better understand the interplay of expected immorality and perceived intentionality by measuring both variables in one study. Second, we addressed a potential confound in our autonomy and influence manipulation, namely that the influence manipulation might have described a positivelyvalenced other-focused use of power (Torelli \& Shavitt, 2010), whereas the autonomy manipulation might have described a negatively-valenced self-focused use of power. Finally, we also included a power manipulation check to test whether our autonomy and influence-manipulations would also affect perceived power. As we observed different patterns in Studies 2 and 3, we had no clear hypotheses regarding which pattern we would observe in Study 4 .

\section{Method}

\section{Participants and Design}

As in Study 3, we aimed for a sample size of 950. To compensate for potential exclusions, we recruited 1,016 MTurk users for US\$0.75, and randomly assigned them to one of four conditions, as in Studies 2 and 3.

We again used a hidden attention check. Thirty-four participants provided no correct response to this check and were thus excluded from data analyses following our 


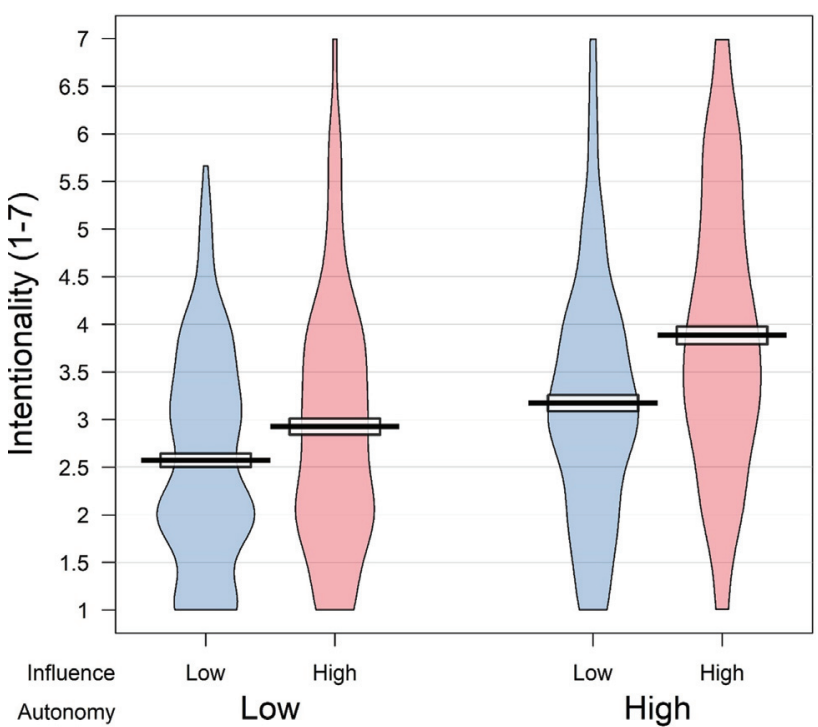

Figure 5. Pirate plot showing attributed intentionality as a function of perceived autonomy and influence in Study 3.

preregistration, leaving a final sample size of 983 individuals (505 male, 471 female, 7 diverse; $M_{\text {age }}=41.20, S D=$ 13.14).

\section{Autonomy and Influence Manipulation}

First, participants read a description (as in Studies 2 and 3), describing a person (John) who either had high or low influence and high or low autonomy. Participants were again asked to read the description and to imagine the person's typical behavior. Compared to the previous studies, we revised the wording. We removed information about whether other people get in John's way, which might have indicated a self-focused use of power, and on whether John is a leader for others, which might have indicated an other-focused use of power. Instead, we now wrote in the high autonomy and high influence-conditions (texts for the low autonomy and low influence conditions are presented in parentheses):

John is pretty (not very) autonomous in his everyday life. Usually, he can (cannot) do whatever he wants and (he cannot) make free decisions. He has a lot of (very little) control over his own life.

$\mathrm{He}$ is not only also (In addition to being not) very autonomous, he also has (does not have) the capacity to control other people. He has (does not have) employees and (or) other individuals that he is in charge of, and he is typically (not) influencing others.

\section{Manipulation Check}

Participants indicated whether the described person "is autonomous," "has influence over other people," and "is powerful" on 7-point rating items ranging from 1 (= disagree) to 7 (= agree).

\section{Expected Immorality and Perceived Intentionality}

Expected immorality $(\alpha=.89)$ and perceived intentionality in a tax evasion scenario $(\alpha=.79)$ were measured with the same items as in Studies 2 and 3, respectively. The immorality and intentionality measures were presented in randomized order.

As seemingly the last item of the intentionality scale, the hidden attention check ("If you read this, choose very unlikely") was administered.

\section{Demographics}

As in the previous studies, participants finally reported their age, gender, and social class, were provided with contact details for further questions and were rewarded through the MTurk online system.

\section{Results}

\section{Manipulation Checks}

The manipulation checks indicated that our manipulations were successful (both $p \mathrm{~s}<.001$, both $d \mathrm{~s}>3.49$, see ESM 1). Moreover, we observed no significant effect of our autonomy manipulation on the influence manipulation check and vice versa (both $p$ s $>.151$, both $d$ s $<0.10$, see ESM 1). Interestingly, perceived power was also increased by both autonomy, $t(981)=15.68, p<.001, d=1.00$, $95 \%$ CI [0.87, 1.13], and influence, $t(981)=21.57, p<$ $.001, d=1.38,95 \%$ CI $[1.24,1.52]$.

\section{Main Analyses}

As predicted, ratings of expected immorality and perceived intentionality were highly correlated across the whole sample, $r(981)=.50,95 \%$ CI $[.45, .54], p<.001$, and within each condition (all $r s>.40$, all $p s<.001$ ). We moreover observed identical result patterns for both dependent variables (see below).

Regarding expected immorality, an ANOVA revealed significant main effects of autonomy, $F(1,979)=19.64, p<$ $.001, \eta_{\mathrm{p}}^{2}=.020,90 \%$ CI $[.008, .036]$, and influence, $F(1,979)=37.69, p<.001, \eta_{\mathrm{p}}^{2}=.037,90 \%$ CI [.020, .058], but no significant interaction, $F(1,979)=0.16, p=$ $.686, \eta_{\mathrm{p}}^{2}<.001,90 \%$ CI [.000, .004]

Likewise, regarding perceived intentionality, an ANOVA revealed significant main effects of autonomy, $F(1,979)=$ $46.81, p<.001, \eta_{\mathrm{p}}^{2}=.046,90 \%$ CI [.027, .069], and influence, $F(1,979)=62.14, p<.001, \eta_{\mathrm{p}}^{2}=.060,90 \% \mathrm{CI}[.038$, .085], but no significant interaction, $F(1,979)=3.05, p=$ $.081, \eta_{p}^{2}=.003,90 \%$ CI [.000, .012]. These patterns are presented in Figures 6 and 7.

\section{Order Effects}

As our dependent variables were presented in randomized order, we also exploratory tested for potential interactions 


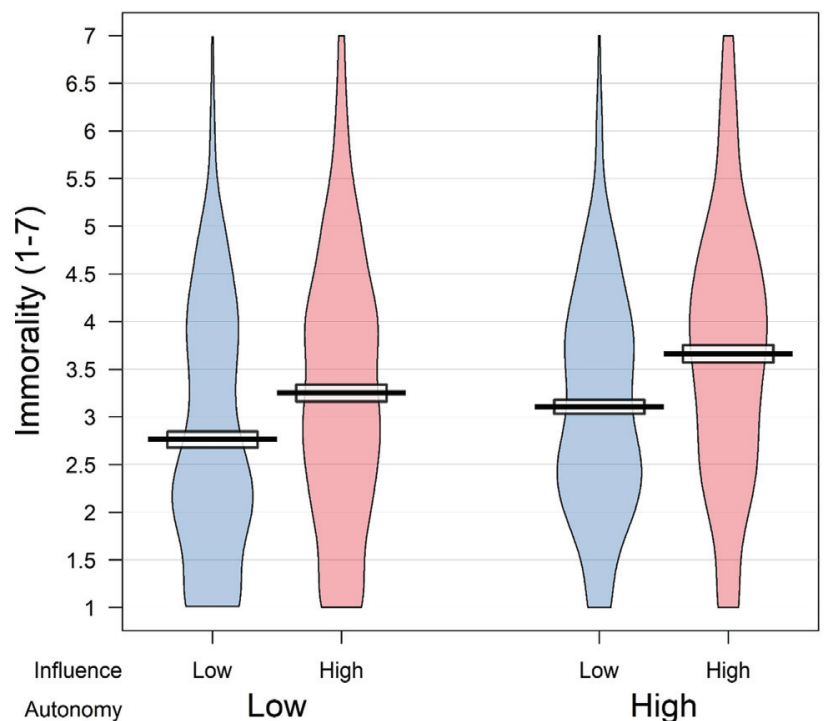

Figure 6. Pirate plot showing expected immorality as a function of perceived autonomy and influence in Study 4.

with this order. While most of these interactions were nonsignificant and did not meaningfully affect the pattern of the results pattern (see ESM 1), it should be noted that the effect of autonomy on expected immorality disappeared when expected immorality was assessed first, resulting in a significant Autonomy $\times$ Order Interaction $\left(p=.001, \eta_{p}^{2}=\right.$ .011 , see ESM 1). However, given that these analyses were non-preregistered and fully exploratory, this should be interpreted with caution.

\section{Discussion}

In Study 4, perceived autonomy and influence were each associated with both expected immorality and perceived intentionality. Our findings are thus in line with Studies 1 and 3 and suggest that autonomy and influence both lead to perceptions of immorality. Importantly, we did not replicate the interaction pattern found in Study 2, suggesting that the findings from Study 2 might be non-replicable. We return to this in the general discussion.

\section{General Discussion}

In the current research, we explored the role of autonomy and influence for beliefs about power, and especially for the belief that the powerful are immoral. Study 1 provided strong evidence that autonomy and influence are central to this belief. First, power had very strong effects on both perceived autonomy and perceived influence. Second, perceived autonomy and perceived influence fully mediated

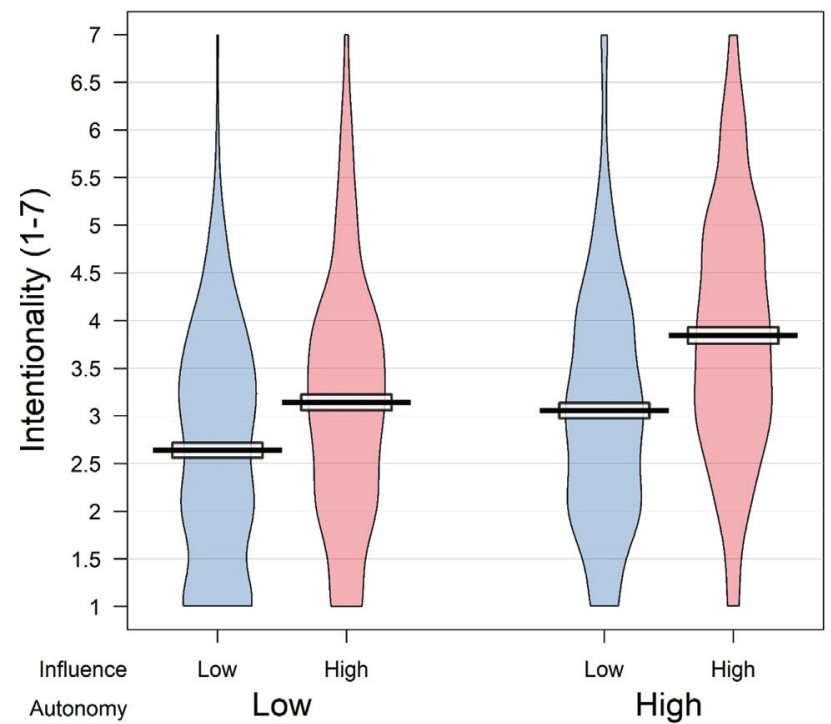

Figure 7. Pirate plot showing attributed intentionality as a function of perceived autonomy and influence in Study 4.

the link between power and expected immorality. When experimentally testing their causal effects, we observed effects of autonomy and influence (Studies 3 and 4) or their interaction (Study 2), again highlighting their importance for beliefs about power.

Interestingly, we observed different patterns across the studies. Study 1 (correlational design) and Studies 3 and 4 (experimental designs) observed parallel effects of autonomy and influence on expected immorality and perceived intentionality. In contrast, Study 2, revealed an interaction: individuals described as low on autonomy but high on influence were perceived as less immoral than all other groups. What could explain these different patterns? Given that the $p$-value in Study 2 was just significant, it seems possible that this finding was a false positive (Benjamin et al., 2018). This would also explain while we failed to replicate the effect in Study 4 . Another explanation, especially for the differences between Studies 2 and 4, might be that we used slightly different manipulations. More specifically, in Study 2 autonomy might have been conflated with a self-oriented and influence with an other-oriented use of power (Torelli \& Shavitt, 2010), which could have led to different results compared to the cleaner manipulation used in Study 4 . Nevertheless, both explanations (i.e., false-positive finding versus a potential confound) suggest that the results of Study 2 might lack credibility, and we thus refrain from further discussing them in detail.

Overall, our findings support the relevance of autonomy and influence for the beliefs about power and (except for the non-replicable Study 2) suggest that both autonomy and influence, are associated with expected immorality. This was the case for general expected immorality (Studies 
1 and 4) and for perceived intentionality in a tax evasion scenario (Studies 3 and 4). Thus, even though many individuals desire autonomy and influence (Lammers et al., 2016), others associate both aspects of power with immoral behavior, which can have detrimental consequences. People might for example stop trusting and cooperating with autonomous and influential individuals (Soderberg, 2017), or, as in our studies, punish them more harshly when given the opportunity.

Our findings, however, also provide useful directions for how to improve people's negative perception of power. In line with our theorizing, non-scientists perceived the powerful as both autonomous and influential (Study 1) and associated autonomy and influence with power (Study 4). Moreover, both aspects of power were associated with immorality. This suggests that changing the perception of any of these aspects, but ideally both, could improve the reputation of powerful individuals. For example, powerful managers could highlight measures that protect the powerless from their influence, such as employment rights or tenancy laws. Likewise, they could highlight how their autonomy is restricted by regulations, supervisory boards, or behavioral codices. If such measures do not exist, introducing them could be an effective strategy to reduce perceptions of immorality and intentionality in case of misbehaviors. Nevertheless, given some inconsistencies across our studies, namely the interaction found in Study 2 and an unpredicted order-effect observed in Study 4, future confirmatory research is needed before drawing strong conclusions and advising policy based on our findings.

Future research could also address another relevant limitation of the present findings. Across studies, we compared low with high levels of autonomy and influence. Future research could add control conditions (e.g., medium levels of autonomy and influence) to test whether our effects are rather driven by the high or by the low-conditions. Even though we believe that the relationship would be linear (i.e., medium conditions scoring in the middle), other patterns seem possible. For example, recent work regarding the perception of social groups found that the relationship between agency (related to power) and communion (related to morality) is curvilinear (Imhoff \& Koch, 2017). Thus, adding control conditions could be an important direction for future research.

Overall, we derive three key insights from the present research. First, in line with our theorizing, non-scientists also associate power with both autonomy and influence. This suggests that autonomy and influence should be considered when studying the social perception of power. Second, autonomy and influence were both associated with expected immorality, suggesting that they play an important role in the belief that the powerful are immoral.
Third, as a consequence, reducing perceived (or actual) autonomy and influence might be a successful strategy to improve the moral reputation of the powerful, thereby reducing conflict and foster cooperation within hierarchies. However, considering some inconsistent findings, future confirmatory research is needed. To sum up, our findings highlight the theoretical and applied importance of autonomy and influence for beliefs about power, but also call for future research on this important topic. The present research constitutes a central starting point for this endeavor.

\section{Electronic Supplementary Material}

The electronic supplementary material is available with the online version of the article at https://doi.org/10.1027/ 1864-9335/a000453

ESM 1. Detailed results for the manipulation checks (Studies 1-4), moderation analyses regarding age, gender, and subjective social class (Studies 1-4), and further supplementary analyses.

\section{References}

Adler, N. E., Epel, E. S., Castellazzo, G., \& Ickovics, J. R. (2000). Relationship of subjective and objective social status with psychological and physiological functioning: Preliminary data in healthy, White women. Health Psychology, 19(6), 586-592. https://doi.org/10.1037/0278-6133.19.6.586

Belmi, P., \& Laurin, K. (2016). Who wants to get to the top? Class and lay theories about power. Journal of Personality and Social Psychology, 111(4), 505-529. https://doi.org/10.1037/ pspi0000060

Benjamin, D. J., Berger, J. O., Johannesson, M., Nosek, B. A., Wagenmakers, E.-J., Berk, R., Bollen, K. A., Brembs, B., Brown, L., \& Camerer, C. (2018). Redefine statistical significance. Nature Human Behaviour, 2(1), 6-10. https://doi.org/10.1038/ s41562-017-0189-z

Brehm, J. W. (1966). A theory of psychological reactance. Academic Press.

Bullock, J. G., Green, D. P., \& Ha, S. E. (2010). Yes, but what's the mechanism? (don't expect an easy answer). Journal of Personality and Social Psychology, 98(4), 550-558. https://doi.org/ 10.1037/a0018933

Champely, S., Ekstrom, C., Dalgaard, P., Gill, J., Weibelzahl, S., Anandkumar, A., Ford, C., Volcic, R., De Rosario, H., \& De Rosario, M. H. (2018). Package "pwr". https://cran.r-project. org/web/packages/pwr/pwr.pdf

Chen, S., Lee-Chai, A. Y., \& Bargh, J. A. (2001). Relationship orientation as a moderator of the effects of social power. Journal of Personality and Social Psychology, 80(2), 173-187. https://doi.org/10.1037/0022-3514.80.2.173

Cislak, A., Cichocka, A., Wojcik, A. D., \& Frankowska, N. (2018). Power corrupts, but control does not: What stands behind the effects of holding high positions. Personality and Social Psychology Bulletin, 44(6), 944-957. https://doi.org/10.1177/ 0146167218757456 
Deci, E. L., \& Ryan, R. M. (2000). The "what" and "why" of goal pursuits: Human needs and the self-determination of behavior. Psychological Inquiry, 11(4), 227-268. https://doi.org/10.1207/ S15327965PLI1104_01

Dubois, D., Rucker, D. D., \& Galinsky, A. D. (2015). Social class, power, and selfishness: When and why upper and lower class individuals behave unethically. Journal of Personality and Social Psychology, 108(3), 436-449. https://doi.org/10.1037/ pspi0000008

Faul, F., Erdfelder, E., Lang, A.-G., \& Buchner, A. (2017). G*Power version 3.1.9.2. http://www.gpower.hhu.de/en.html

Fiedler, K., Schott, M., \& Meiser, T. (2011). What mediation analysis can (not) do. Journal of Experimental Social Psychology, 47(6), 1231-1236. https://doi.org/10.1016/j.jesp.2011. 05.007

Fiske, S. T. (2010). Interpersonal stratification: Status, power, and subordination. In S. T. Fiske, D. T. Gilbert, \& G. Lindzey (Eds.), Handbook of social psychology (pp. 941-982). Wiley.

Fiske, S. T., \& Berdahl, J. (2007). Social power. In A. W. Kruglanski \& E. T. Higgins (Eds.), Social psychology, second edition: Handbook of basic principles (2nd ed., pp. 678-692). Guilford Publications.

Fragale, A. R., Overbeck, J. R., \& Neale, M. A. (2011). Resources versus respect: Social judgments based on targets' power and status positions. Journal of Experimental Social Psychology, 47, 767-775. https://doi.org/10.1016/j.jesp.2011.03.006

Fragale, A. R., Rosen, B., Xu, C., \& Merideth, I. (2009). The higher they are, the harder they fall: The effects of wrongdoer status on observer punishment recommendations and intentionality attributions. Organizational Behavior and Human Decision Processes, 108(1), 53-65. https://doi.org/10.1016/j.obhdp. 2008.05.002

French, J. R., \& Raven, B. (1959). The bases of social power. In D. Cartwright (Ed.), Studies in social power (Vol. 7, pp. 150-167). Institute for Social Research.

Galinsky, A. D., Gruenfeld, D. H., \& Magee, J. C. (2003). From power to action. Journal of Personality and Social Psychology, 85(3), 453-466. https://doi.org/10.1037/0022-3514.85.3.453

Guinote, A. (2007). Power and goal pursuit. Personality and Social Psychology Bulletin, 33(8), 1076-1087. https://doi.org/10.1177/ 0146167207301011

Guinote, A., Weick, M., \& Cai, A. (2012). Does power magnify the expression of dispositions? Psychological Science, 23(5), 475-482. https://doi.org/10.1177/0956797611428472

Hauser, D. J., \& Schwarz, N. (2016). Attentive Turkers: MTurk participants perform better on online attention checks than do subject pool participants. Behavior Research Methods, 48, 400-407. https://doi.org/10.3758/s13428-015-0578-z

Hays, N. A. (2013). Fear and loving in social hierarchy: Sex differences in preferences for power versus status. Journal of Experimental Social Psychology, 49(6), 1130-1136. https://doi. org/10.1016/j.jesp.2013.08.007

Hirsh, J. B., Galinsky, A. D., \& Zhong, C.-B. (2011). Drunk, powerful, and in the dark: How general processes of disinhibition produce both prosocial and antisocial behavior. Perspectives on Psychological Science, 6(5), 415-427. https://doi.org/10.1177/ 1745691611416992

Hu, M., Rucker, D. D., \& Galinsky, A. D. (2016). From the immoral to the incorruptible: How prescriptive expectations turn the powerful into paragons of virtue. Personality and Social Psychology Bulletin, 42(6), 826-837. https://doi.org/10.1177/ 0146167216644428

Imhoff, R., \& Bruder, M. (2014). Speaking (un-)truth to power: Conspiracy mentality as a generalised political attitude. European Journal of Personality, 28(1), 25-43. https://doi.org/ 10.1002/per.1930
Imhoff, R., \& Koch, A. (2017). How orthogonal are the Big Two of social perception? On the curvilinear relation between agency and communion. Perspectives on Psychological Science, 12(1), 122-137. https://doi.org/10.1177/1745691616657334

Keltner, D., Gruenfeld, D. H., \& Anderson, C. (2003). Power, approach, and inhibition. Psychological Review, 110(2), 265284. https://doi.org/10.1037/0033-295X.110.2.265

Lakens, D. (2014). Calculating confidence intervals for Cohen's $d$ and eta-squared using SPSS, R, and Stata. http://daniellakens. blogspot.ca/2014/06/calculating-confidence-intervals-for.html

Lammers, J., \& Imhoff, R. (2016). Power and sadomasochism: Understanding the antecedents of a knotty relationship. Social Psychological and Personality Science, 7(2), 142-148. https:// doi.org/10.1177/1948550615604452

Lammers, J., Stoker, J. I., Rink, F., \& Galinsky, A. D. (2016). To have control over or to be free from others? The desire for power reflects a need for autonomy. Personality and Social Psychology Bulletin, 42(4), 498-512. https://doi.org/10.1177/ 0146167216634064

Lammers, J., Stoker, J. I., \& Stapel, D. A. (2009). Differentiating social and personal power: Opposite effects on stereotyping, but parallel effects on behavioral approach tendencies. Psychological Science, 20(12), 1543-1548. https://doi.org/10.1111/ j.1467-9280.2009.02479.x

Leach, S., Weick, M., \& Lammers, J. (2017). Does influence beget autonomy? Clarifying the relationship between social and personal power. Journal of Theoretical Social Psychology, 1(1), 5-14. https://doi.org/10.1002/jts5.5

McClelland, D. C. (1970). The two faces of power. Journal of International Affairs, 24(1), 29-47.

Phillips, N. (2017). Yarrr: A companion to the e-book "yarrr!: The pirate's guide to r". https://cran.r-project.org/package=yarrr

Sassenberg, K., Ellemers, N., \& Scheepers, D. (2012). The attraction of social power: The influence of construing power as opportunity versus responsibility. Journal of Experimental Social Psychology, 48(2), 550-555. https://doi.org/10.1016/ j.jesp.2011.11.008

Schmid Mast, M., \& Hall, J. A. (2003). Anybody can be a boss but only certain people make good subordinates: Behavioral impacts of striving for dominance and dominance aversion. Journal of Personality, 71(5), 871-892. https://doi.org/10.1111/ 1467-6494.7105007

Soderberg, A. (2017). Can you expect the boss to be ethical? Effects of boss' status and power on subordinates' trust. Academy of Management Proceedings, 2017, Article 17094. https://doi.org/10.5465/AMBPP.2017.17094abstract

Spencer, S. J., Zanna, M. P., \& Fong, G. T. (2005). Establishing a causal chain: Why experiments are often more effective than mediational analyses in examining psychological processes. Journal of Personality and Social Psychology, 89(6), 845-851. https://doi.org/10.1037/0022-3514.89.6.845

Steindl, C., Jonas, E., Sittenthaler, S., Traut-Mattausch, E., \& Greenberg, J. (2015). Understanding psychological reactance. Zeitschrift für Psychologie, 223, 205-214. https://doi.org/ 10.1027/2151-2604/a000222

Tavoni, A., Dannenberg, A., Kallis, G., \& Löschel, A. (2011). Inequality, communication, and the avoidance of disastrous climate change in a public goods game. Proceedings of the National Academy of Sciences, 108(29), 11825-11829. https:// doi.org/10.1073/pnas.1102493108

Thomas, A. J., Sumner, E., \& Sarnecka, B. W. (2020). Children expect leaders to oust intruders, to refrain from aggression, but do not expect leaders to be generally more prosocial [Preprint]. PsyArXiv. https://doi.org/10.31234/osf.io/txvsd

Torelli, C. J., \& Shavitt, S. (2010). Culture and concepts of power. Journal of Personality and Social Psychology, 99(4), 703-723. 
Van Dijke, M., \& Poppe, M. (2006). Striving for personal power as a basis for social power dynamics. European Journal of Social Psychology, 36(4), 537-556. https://doi.org/10.1002/ejsp.351

Wallimann, I., Tatsis, N. C., \& Zito, G. V. (1977). On Max Weber's definition of power. The Australian and New Zealand Journal of Sociology, 13(3), 231-235.

Wingen, T., Englich, B., Estal-Muñoz, V., Mareva, S., \& Kassianos, A. P. (2020). Exploring the relationship between social class and quality of life: The mediating role of power and status. Applied Research in Quality of Life. Advance online publication. https://doi.org/10.1007/s11482-020-09853-y

Winter, D. G. (1973). The power motive. Free Press.

\section{History}

Received May 28, 2020

Revision received June 7, 2021

Accepted June 7, 2021

Published online August 11, 2021

\section{Acknowledgments}

We thank Nicolas Alef, Amelie Conrad, Antonia Dörnemann, Elisabeth Jackson, and Estella Umbach for their valuable support with the grant and ethics applications, and the final manuscript. We thank Joris Lammers and Andrea Wingen for their very helpful comments. We would like to dedicate this paper to the memory of Birte Englich, who contributed greatly to the development of this research project. We are grateful for her help and support during this project and way beyond.

\section{Authorship}

Tobias Wingen developed the study concept and study design, and collected and analyzed the data. Simone Dohle assisted in the interpretation of the data. Tobias Wingen drafted the manuscript, and Simone Dohle provided critical revisions. Both authors read and approved the final manuscript.

\section{Publication Ethics}

This research project was reviewed and approved by the local institutional review board.

\section{Open Data}

Materials, data, analyses syntaxes, and preregistrations are shared on https://osf.io/qfjtv/.

\section{Funding}

This research was supported by a C-SEB Junior Start-Up Grant awarded to Tobias Wingen and by a DFG Grant (DO 1900/3-1) awarded to Simone Dohle. Open access publication enabled by University of Cologne.

\section{ORCID}

Tobias Wingen

(iD https://orcid.org/0000-0002-1559-859X

Simone Dohle

(iD) https://orcid.org/0000-0003-1535-5464

\section{Tobias Wingen}

Applied Social Psychology and Decision Making

Social Cognition Center Cologne

University of Cologne

Richard-Strauss-Straße 2

50931 Cologne

Germany

tobias.wingen@uni-koeln.de 